This item was submitted to Loughborough's Research Repository by the author.

Items in Figshare are protected by copyright, with all rights reserved, unless otherwise indicated.

\title{
Design and performance of thin, circular arc, wind-tunnel turning vanes
}

PLEASE CITE THE PUBLISHED VERSION

http://www.raes.org.uk/aero_journal.asp

\section{PUBLISHER}

(c) Royal Aeronautical Society

\section{VERSION}

VoR (Version of Record)

\section{LICENCE}

CC BY-NC-ND 4.0

\section{REPOSITORY RECORD}

Johl, G., Martin A. Passmore, and Peter M. Render. 2010. "Design and Performance of Thin, Circular Arc, Wind-tunnel Turning Vanes". figshare. https://hdl.handle.net/2134/6675. 
This item was submitted to Loughborough's Institutional Repository (https://dspace.lboro.ac.uk/) by the author and is made available under the following Creative Commons Licence conditions.

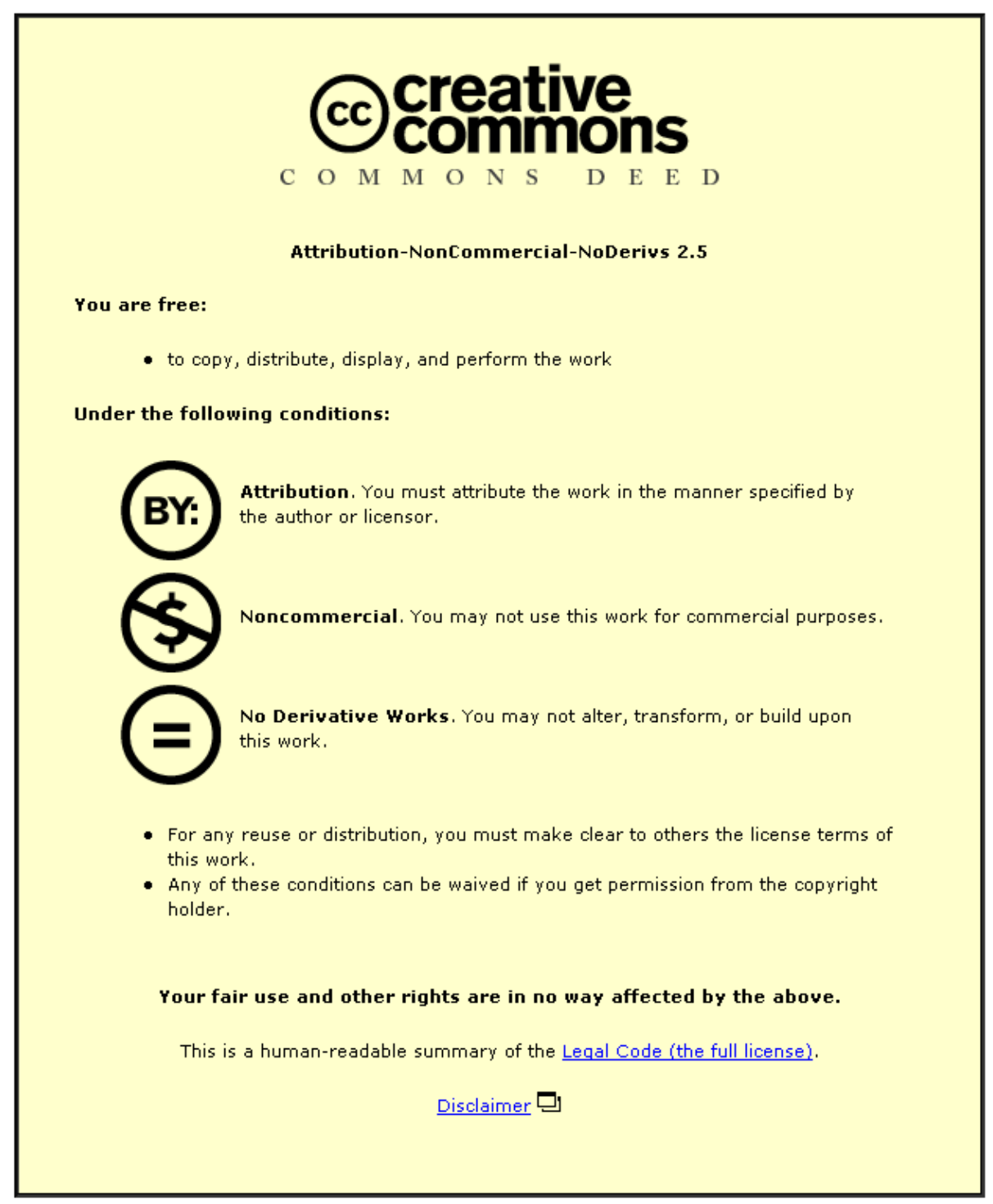

For the full text of this licence, please go to: http://creativecommons.org/licenses/by-nc-nd/2.5/ 


\title{
Design and performance of thin, circular arc, wind-tunnel turning vanes
}

\author{
G. Johl, M. Passmore and P. Render \\ Department of Aeronautical and Automotive Engineering \\ Loughborough University \\ Loughborough, UK
}

\subsection{INTRODUCTION}

Although test rig data exists for $1 / 4$ circle turning vanes, the actual performance of these vanes once installed in a wind tunnel, and the extent to which test rig results are replicated, is rarely known. This paper compares pressure loss coefficient and velocity profile data from a vane test module with measurements taken in the low speed wind tunnel described in Ref. 1 . The pressure loss coefficient, $K_{L}$ is defined as the ratio between the static pressure loss in a corner and the inlet dynamic pressure:

$$
K_{L}=\frac{p_{1}-p_{2}}{1 / 2 \rho U_{1}^{2}}
$$

Where, $p$ is the static pressure, $\rho$ is the air density and $U$ is the mean velocity, and subscripts 1 and 2 indicate upstream and downstream.

Previous investigations in test rigs have shown that thin $1 / 4$ circle turning vanes with a space to chord ratio $(s / c)$ of between $0 \cdot 20-0 \cdot 25$, produced $0.12<K_{L}<0.20^{(2)(3)(4)(5)}$. However, these sources focused on determining $K_{L}$ rather than quantifying the flow quality downstream of the vanes. Although $K_{L}$, is important in terms of achieving a high tunnel energy ratio, it is perhaps secondary to downstream flow quality since the stream exiting the corners of a typical wind tunnel enter into components whose performance may be affected by flow quality.

\subsection{VANE TEST MODULE}

A constant area vane test module was constructed to enable $K_{L}$ and velocity profile data to be obtained for vanes of the same chord as that used in the corners of the wind tunnel. The span of the test vanes was limited to $450 \mathrm{~mm}$, since the test module had to mate to the end of the working section of an existing blower wind tunnel. The wind tunnel had a turbulence intensity of $0.1 \%$ in the working section, which was similar to the value of $0.15 \%$ for the wind tunnel of Ref. 1 . Tests were performed at the chord Reynolds number $\left(R_{e c}\right)$ seen in the second corner of the wind tunnel when running at its design speed.

As shown in Fig. 1, the vanes were designed with an angle-ofattack of $4^{\mathrm{o}(4)}$, since $K_{L}$ is a minimum for a vane cascade at around this angle ${ }^{(6)}$. Since $K_{L}$ reduces with increasing $R_{e c}$, it was decided to employ vanes of large chord $(c)$. Aside from the aerodynamic benefit, vanes of large chord are more rigid and also reduces the number of vanes, and hence cost, required for a given $s / c$. The test vanes were constructed from $1.5 \mathrm{~mm}$ thick rolled aluminium with an inside radius, $r, 245 \mathrm{~mm}$. To encourage the flow to leave the vanes axially, a trailing-edge extension (TE) of $165 \mathrm{~mm}$ was employed. This geometry resulted in a chord, $c$, of $468.5 \mathrm{~mm}$, which gave an $R_{e c}$ of $5.74 \times 10^{5}$ during tests.

The vane test module is shown in Fig. 2. With three vanes installed an $s / c$ of 0.237 was achieved, which was as close as it was possible to get to the $s / c$ of $0 \cdot 25$ suggested by most sources for 


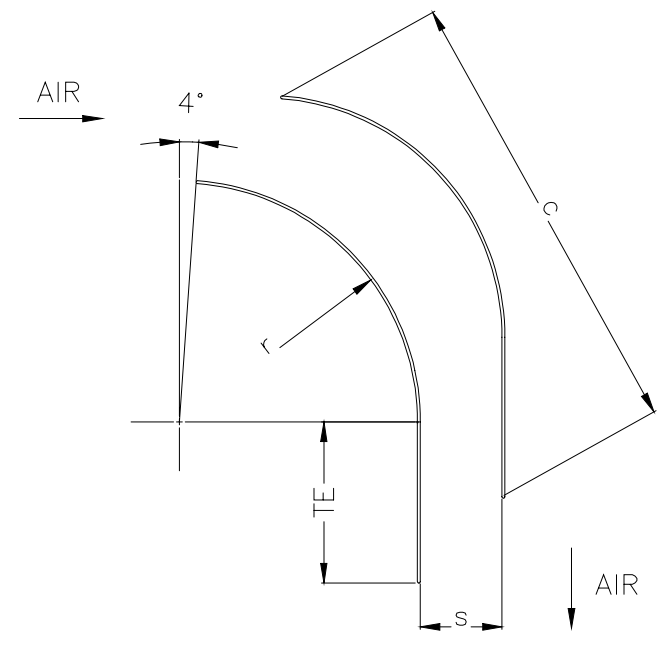

Figure 1. Turning vane used in test module and wind tunnel.

minimum $K_{L}$. However, since one investigator had proposed that greater stability of the near wall stream may be obtained by employing an $s / c$ of $0.20^{(4)}$, a fourth vane was added to the test module (producing an $s / c$ of 0.190 ) to enable additional tests to evaluate this suggestion.

The pressure loss coefficient, $K_{L}$, was determined by measuring the static pressure loss across the cascade and dividing this by the dynamic pressure in the working section of the blower wind tunnel to which the test module was mated. Static pressure loss across the cascade was measured by means of the averaged reading from a ring of static tappings located at positions $A$ and $B$ on Fig. 3. $A$ and $B$ were respectively located $25 \mathrm{~mm}$ upstream and $25 \mathrm{~mm}$ downstream of the inner bend of the cascade. An additional ring of tappings was provided at $C$. Each ring comprised four tappings located at the midpoint on each side of the module.

Velocity profiles were measured perpendicular to the test module walls at locations $A, B$ and $C$ using a pitot probe referenced to the averaged reading from the relevant ring of wall static tappings. The flow was ejected to atmosphere $600 \mathrm{~mm}$ downstream of location $C$. The head of the pitot was placed in the same plane as the tappings, and was traversed across the mid span of the vanes in $10 \mathrm{~mm}$ increments. The pitot probe was constructed from tubing with an outside diameter of $3.3 \mathrm{~mm}$ and an inside diameter of $2.5 \mathrm{~mm}$.

For both pressure loss and velocity profile measurements, differential pressure transducers with an accuracy of $0.25 \%$ of reading was used. Data was sampled at $1 \mathrm{kHz}$ for 10 seconds and averaged over ten repeats to promote confidence in the mean. A two-minute settling time was allowed between readings since the tubing used was necessarily long.

\subsubsection{Test module results}

The velocity profiles presented in Figs 3 and 4, are non-dimensionalised by dividing the local axial velocity, $u$, measured by the traversed pitot, with the freestream velocity, $U$, measured by a pitot static in the working section of the blower wind tunnel.

Figure 3 shows that $25 \mathrm{~mm}$ upstream of the cascade, the flow exhibits a flat velocity profile with inner and outer wall boundarylayers that are free from reversed flow. Continuity of flow through the test module, leads to $u / U$ being slightly greater than 1.0 outside of the boundary layers. Downstream of the cascade, the observed velocity minima are in line with the trailing edges of the vanes. The vane wakes for both $s / c$ 's tested, show a greater deficit on the suction side of the vane, that is due to a thicker boundary-layer. The

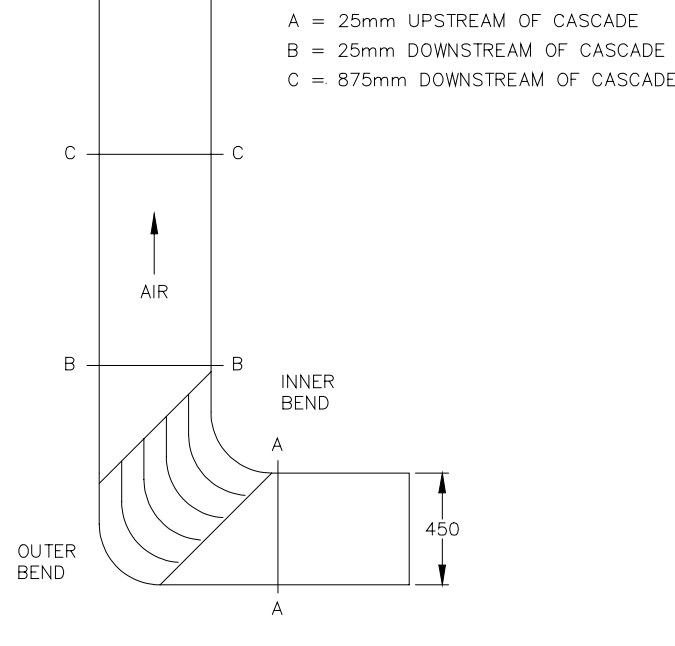

Figure 2. Vane test module with four vanes installed.

additional work performed by the three vane cascade compared to the four vane is evidenced by the larger wakes and lower velocity minima produced by the former. $K_{L}$ data for the two $s / c$ 's investigated, are shown in Table 1 , and it is clear that there is little difference between the two configurations.

Table 1

$\begin{array}{cc}\boldsymbol{K}_{L} \text { values at } \mathbf{R e}_{c} \text { of } \mathbf{5 . 7 4} \times \mathbf{1 0}^{5} \\ \mathbf{I} / \boldsymbol{c} & \boldsymbol{K}_{\boldsymbol{L}} \\ 0.237 & 0.132 \\ 0.190 & 0.128\end{array}$

The value of $K_{L}$ measured at an $s / c$ of 0.237 may be compared to previous test rig data ${ }^{(4)}$, which produced a $K_{L}$ of 0.120 for $1 / 4$ circle vanes at an $s / c$ of 0.25 and an $R_{e c}$ of $2 \times 10^{5}$.

Non-dimensionalised velocity profiles measured $25 \mathrm{~mm}$ upstream, and $875 \mathrm{~mm}$ downstream of the cascade are presented in Fig. 4. Downstream of the cascade, the three-vane configuration shows a significant momentum deficit at the inner bend compared to the four vane set-up. This is surprising given how closely matched the inner wall profiles of the three and four vanes were, $25 \mathrm{~mm}$ downstream of the cascade, but supports the improved near wall stability suggested in Ref. 4. Due to this better inner bend flow quality an $s / c$ of $0 \cdot 190$ was chosen for use in the wind tunnel ${ }^{(1)}$.

\subsection{WIND-TUNNEL RESULTS}

Vanes used in the wind tunnel were identical to those employed in the vane test module except that the thickness was increased to $3 \mathrm{~mm}$ to enhance rigidity. It also enabled more roundness to be applied to the leading edge to make the vanes less sensitive to inlet flow angularity. The internal dimensions at inlet to the second wind tunnel corner were $2,180 \mathrm{~mm}$ high (i.e.: vane span) and $2,630 \mathrm{~mm}$ wide, resulting in 28 vanes in the cascade.

Figure 5 presents velocity profiles measured perpendicular to the tunnel walls at mid span, on the inner and outer bends, $220 \mathrm{~mm}$ upstream and $80 \mathrm{~mm}$ downstream of the corner, which was as close as it was possible to get to the corner's inlet and exit The local widths, $Y$, at the traverse planes shown in Fig. 5, differ from the corner dimensions because of the diffusers located upstream and downstream of the corner. Positive and negative values of $Y$ relate to the inner and outer bends respectively. Velocity profiles were determined using a pitot probe referenced to the averaged reading from a 
$25 \mathrm{~mm}$ Downstream of Cascade

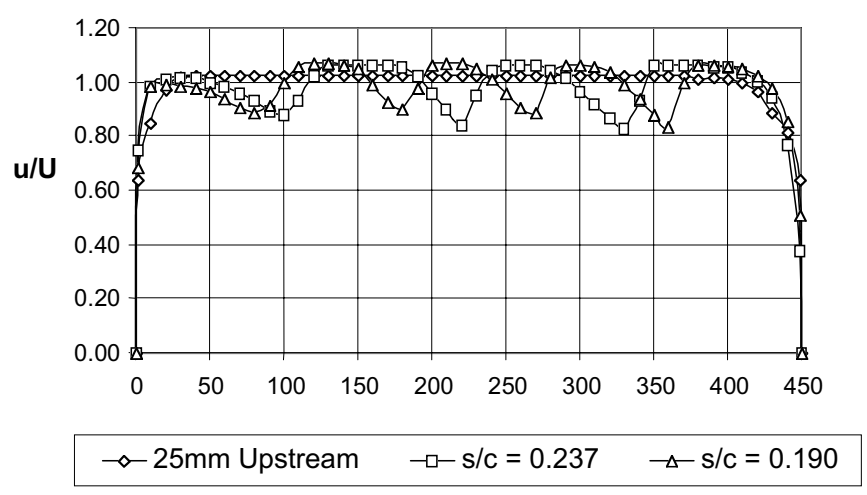

Outside Bend $=0 \mathrm{~mm}$ Inside Bend $=450 \mathrm{~mm}$

Figure 3. Velocity profiles at mid span, measured $25 \mathrm{~mm}$ upstream, and $25 \mathrm{~mm}$ downstream of the cascade.

ring of four wall static tappings. One tapping was located at the mid point of each wall of the wind tunnel in the same plane as the head of the pitot. The probe was traversed across the vanes in $10 \mathrm{~mm}$ increments. The construction of the probe, data acquisition and reduction technique employed were the same as for the vane test module. Remnants of the wakes from the first corner can still be seen in the upstream flow for the inner bend. The different $Y$ location of these wakes is due to the flow having passed through a diffuser. Downstream it can be seen that the wakes from the outer bend have mixed out whilst those from the inner bend have not. This is a consequence of the flow having had to travel further along the outer wall than the inner. Variations can be seen in the wake profiles downstream of the inner bend. This may partly be due to greater mixing towards the outer bend and perhaps also due to local inlet
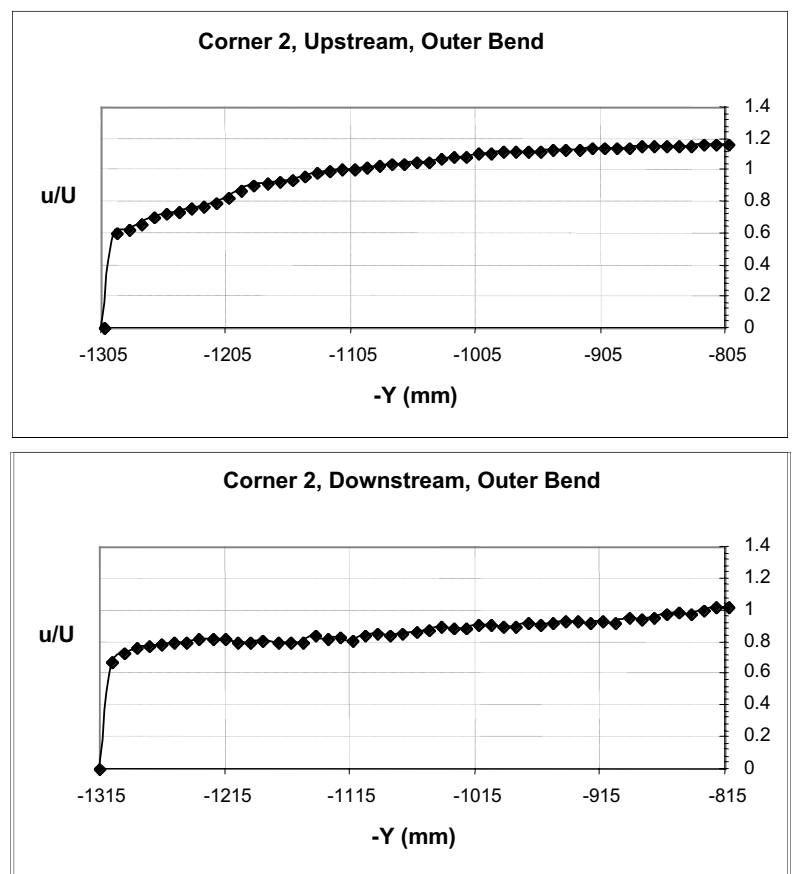

\section{5mm Downstream of Cascade}

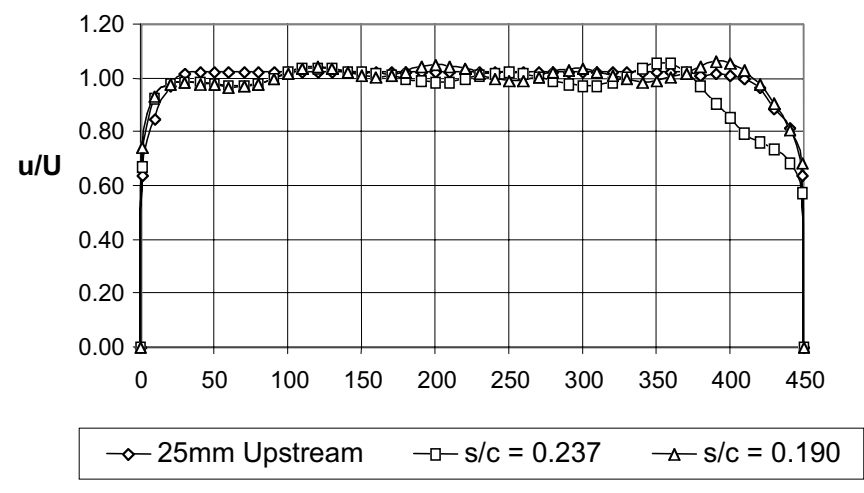

Outside Bend $=0 \mathrm{~mm}$ Inside Bend $=450 \mathrm{~mm}$

Figure 4. Velocity profiles at mid span, measured $25 \mathrm{~mm}$ upstream, and $875 \mathrm{~mm}$ downstream of the cascade.

non-uniformity resulting in variations in the amount of work done by each vane.

To determine $K_{L}$, the static pressure loss was measured by means of the averaged reading from the rings of static tappings located upstream and downstream. This resulted in a $K_{L}$ of 0.160 at an $R_{e c}$ of $5.74 \times 10^{5}$. The difference from the test vane module value is not surprising given that significant differences exist in the upstream velocity profiles, particularly in the wall region. Whilst the differences between the wind tunnel and test module values for $K_{L}$ appear to be large, it should be noted that in absolute terms the difference in pressure loss was seven Pascals.

The possible influence of upstream velocity profile is illustrated by results for the first corner, which was located behind the working section. With an empty working section, the velocity profile was
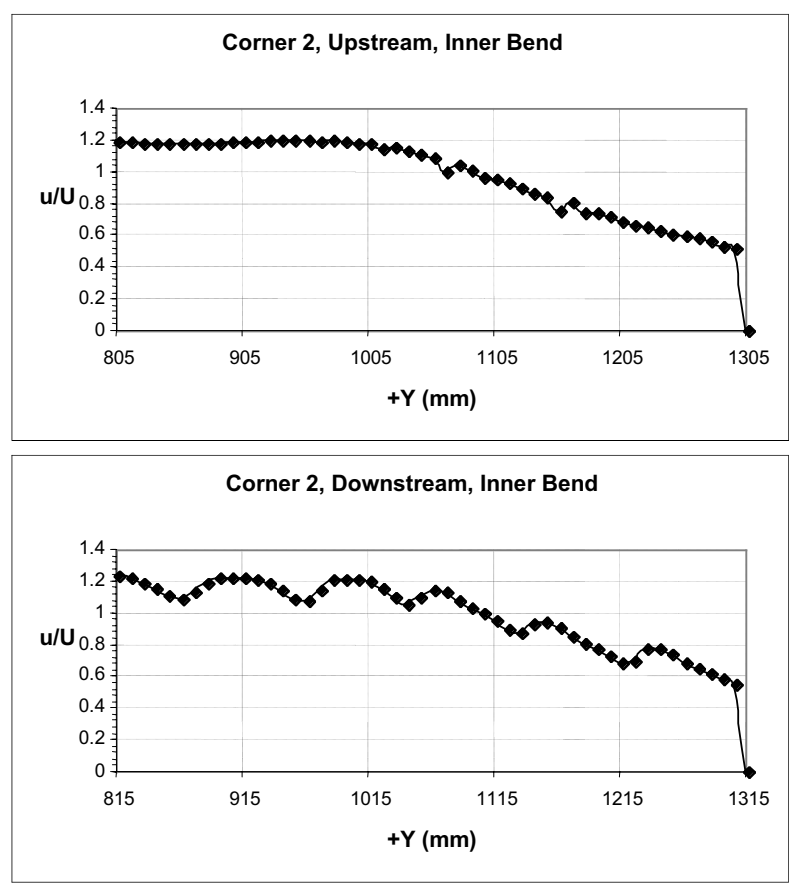

Figure 5. Velocity profiles upstream and downstream of the second corner. 
more uniform than seen for the second corner, and with significantly thinner wall boundary-layers. When run at an Rec of $5.74 \times 10^{5}$, the value of $K_{L}$, was approximately $0 \cdot 109$. The results for the two corners suggest that test rig data can be used to predict pressure losses through vanes, although it may be prudent to factor the $K_{L}$ values for each successive corner.

\subsection{CONCLUSIONS}

- Test module results have shown that $1 / 4$ circle vanes set at space to chord ratios of 0.190 and 0.237 produced comparable boundary layer profiles $25 \mathrm{~mm}$ downstream of the cascade, but that the $s / c=0.237$ cascade produced a momentum deficit in the inner bend boundary-layer further downstream.

- Whilst the vane test module was unable to simulate the boundary layer seen on the wind tunnel walls, $K_{L}$ data derived from the test module is of the correct order to that measured in the wind tunnel.

\section{REFERENCES}

1. Johl, G.S. Passmore, M.A. and Render, P.M. Design methodology and performance of an indraft wind tunnel, Aeronaut $J$, September 2004, 108, (1087), pp 465-473.

2. Klein, G.J. Tupper, K.F. and Green, J.J. The design of corners In fluid channels, Canadian J Research, 3, pp 272-285 (1930).

3. Collar, A.R; Some experiments with cascades of aerofoils, Aeronautical Research Committee Technical Report 1768 (1936).

4. SAlter, C. Experiments on thin turning vanes; reports and memoranda No 2469 (Aerodynamics Division NPL); 25 October 1946.

5. WinteR, K.G. Comparative tests of thick and thin turning vanes in the Royal Aircraft Establishment $4 \mathrm{x} 3 \mathrm{ft}$ wind tunnel; Reports and Memoranda No 2589; August 1947.

6. IdelchiK, I.E. and Fried, E. Flow Resistance, Hemisphere Publishing Corporation, 1989. 